\title{
Long-term and Cross-sectoral Management of Interconnected Events: The Case of the Fukushima Nuclear Accident
}

\author{
Taketoshi Taniguchi \\ University of Tokyo, Tokyo, Japan
}

\author{
Hideaki Shiroyama \\ University of Tokyo, Tokyo, Japan
}

\begin{abstract}
In a world-shocking nuclear disaster occurred at Fukushima in 2011, multi-faceted consequences have manifested in not only direct and indirect but also tangible and intangible way in social, political, and economic domains. At present six year later, original risk issues, such as health, environmental, and financial risks, were complexly connected to each other, and have transformed to the wicked or complicated problems. This paper addresses the following four problems that we are faced with: prolonged evacuation and return to hometown, Tokyo Electric Power Company Holdings issues, nuclear regulatory issues, and nuclear energy policy and business. The authors discuss the reasons why above-noted situations arise from nuclear disaster in terms of endogenous factors embedded in socio-technical nuclear system in Japan and some common causes across the wicked problems. The wicked problems are also closely connected with each other, and become super-wicked problem. Among others, Japan's energy transition policy aiming at low carbon society tends to deviate politically and now at crossroad. Finally, the authors describe some perspectives and challenges required to govern interconnected events, as lessons learned from the Fukushima nuclear disaster.
\end{abstract}

Keywords: Fukushima nuclear disaster, interconnectivity, interdependency, multi-faceted risk, wicked problem

\section{Introduction}

Today's socio-economic activities are becoming more interdependent in an increasingly interconnected complex and dynamic world with a rapid technological progress (Taniguchi, 2016a). Interconnectivity between systems is one of the defining and determining features of our modern world. Risks with systemic nature spread easily over other sectors and systems, and would affect all social subsystems, such as the critical infrastructure, economy, and politics, and eventually would have debilitating impacts on national growth and our daily-life (WEF, 2010). On March 11, 2011, East Japan Earthquake with M9 and the subsequent unprecedented tsunami crippled the Fukushima Daiichi nuclear power station, and disruption of cooling system for the three reactors led to core meltdowns and hydrogen explosions, which caused a release of radioactive materials into the atmosphere and the ocean. Furthermore most notably the accident brought about multi-faceted risks with systemic nature in social, political, and economic domains. The unprecedented natural and man-made disasters have really put this risk landscape of Japanese society into relief (Taniguchi, 2016b; WEF, 2012).

Already six years have passed since a world-shocking nuclear disaster at Fukushima. The nuclear emergency declaration announced in March 11, 2011 still continues, and we are faced with a wide range of

Taketoshi Taniguchi, Professor, Ph.D., Policy Alternatives Research Institute (PARI), University of Tokyo;

Hideaki Shiroyama, Professor, Faculty of Law, Graduate Schools of Law and Politics, University of Tokyo. 
hurdles to deal with multi-faceted risks induced through cascading or ripple effects. This paper addresses four cases of wicked or complicated problems: prolonged evacuation and return to hometown, Tokyo Electric Power Company (TEPCO) Holdings issues, nuclear regulatory issues and nuclear energy policy and business; and discusses common causes across the cases, describes some perspectives and challenges needed for managing or governing the wicked problem.

\section{Why Multi-Faceted Events Have Manifested in Fukushima Nuclear Disaster}

Before the Fukushima accident, nuclear power was a major part of electric power supply system that forms the fundamentals of critical infrastructures in the Japanese society. Besides, so far nuclear power business has been tightly and complexly interconnected with and interdependent on socio-political-economic activities, particularly in the plant hosting areas. The Fukushima nuclear power station operated by TEPCO that was a leader in nuclear power industry, was vital electric power source for metropolitan area. Additionally, looking at the society, public perception and awareness of risks are diversifying due to fragmentation and atomization of society. Moreover, communication tools and devices with different characteristics such as coverage, speed, and capacity, can induce unstable dynamics of risk information delivery. These phenomena amplified risk with systemic nature and induced domino effects. Economic contagions are always accompanied by thought contagions.

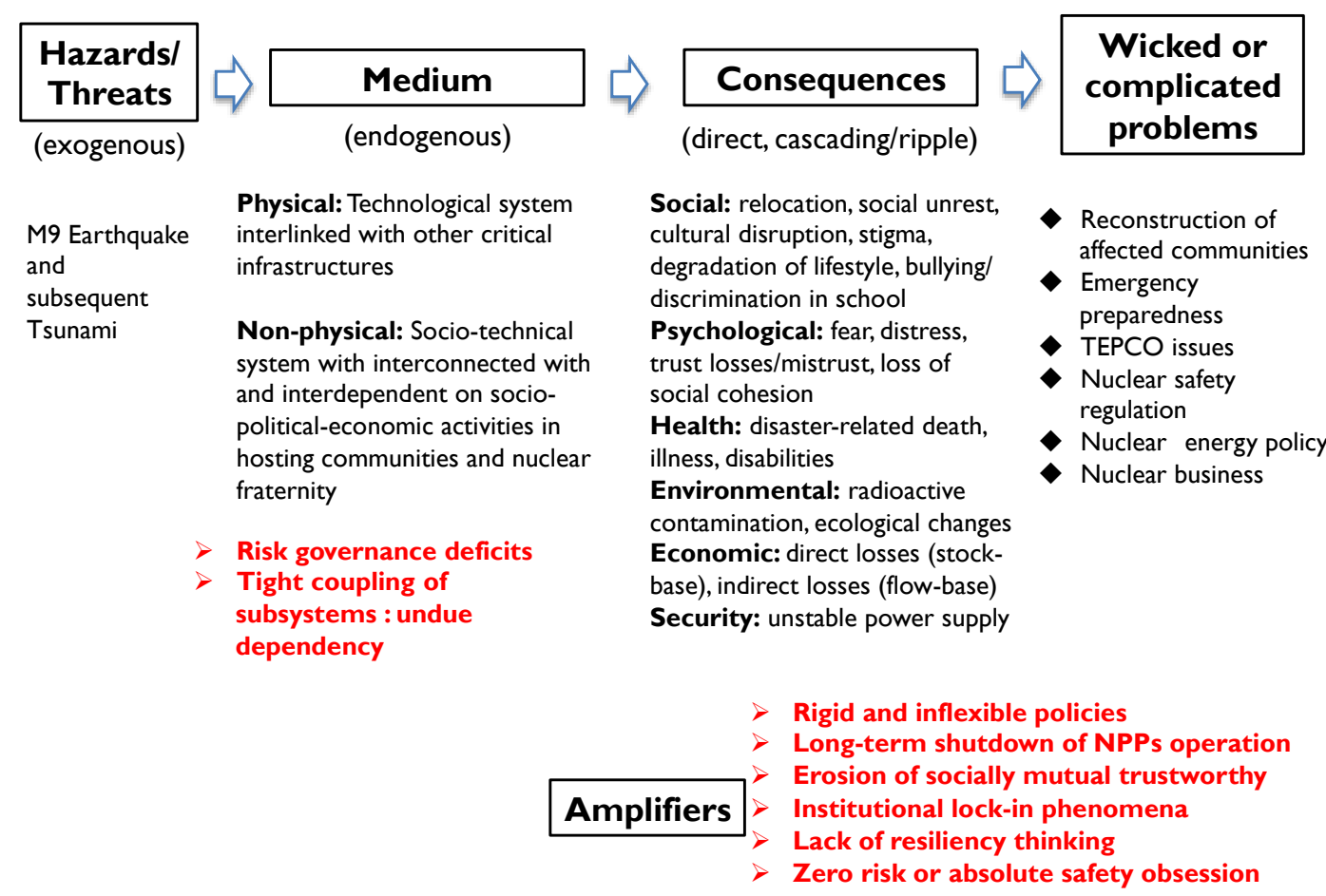

Figure 1. Overview of events/consequences manifested by Fukushima nuclear disaster.

Nuclear meltdown accident occurred in such circumstance. Consequently, as shown in Figure 1, multi-faceted consequences have manifested in not only direct or indirect but also tangible or intangible way in social, political, and economic domains. These are mainly caused by endogenous factors embedded in our 
socio-technical system, that is to say, risk governance deficits in nuclear fraternity and tight coupling of subsystems such as undue dependency.

As for risk governance deficits, according to the deficits analysis of emergency preparedness and response and severe accident management of nuclear power plants in Japan before, during, and after the Fukushima nuclear accident, many serious deficits were observed before the Fukushima (Taniguchi, 2016b). In summary from the viewpoint of seeking integrated approach for better governance, the followings were pointed out.

Firstly, risk-related knowledge base was deficient or inadequate. For emergency preparedness and response and severe accident management policy-making, a wide range of knowledge and information are inevitably needed and should be understood by decision-makers and responders in emergency situation. From these viewpoints, lacks of gathering knowledge about hazards and risks, their early signals, stakeholders' risk perception, interests and concerns were definitely fatal.

Secondly, interface problem among stakeholders was a serious underlying problem. For instance, a failure of interdisciplinary communication can be observed in the phase of risk knowledge generation. Consequently, miss or ignorance of early risk signals occurs.

Thirdly, appreciation or understanding fundamental changes and interdependencies of agents in complex societal system was definitely lacking. During the period that nuclear power generation has planted its roots deeply in Japanese society, socio-economic-political fabric of the society including local communities where nuclear power plants are located has been significantly changing, and therefore, various interests and stakeholders have emerged, and their interdependent relationships became more complicated. Despite these situations, decision-makers and policy-makers in nuclear fraternity, being basically introverted, held only a narrow perspective (myopia). Inward-looking and non-holistic management might hinder awareness of the systemic and multi-faceted natures of many risks of critical infrastructure and economic system advancement.

Fourthly, deficits in legal system and departmentalized emergency response scheme could exacerbate risks and make organizations insensitive to risk. These are obstacles of the All-Hazards and the Whole-of-Government approaches to emergency preparedness and response.

Fifthly, organizational capacity building for managing risks (in particular, specialized competence and knowledge, organizational integration, flexibility and its network) was inadequate. The backdrop of the deficit is an absence of safety culture. Both the regulatory authorities and power companies structurally failed to assimilate "safety culture", which is to reject satisfaction with status quo regarding safety, and diligently pursue autonomous reforms aimed at higher objectives. Instead, "safety culture" remained simply a pleasant sounding slogan without any behaviors for detection, recognition, sharing, assessment, or response to risks.

Lastly, scientific advices were not coordinated in crisis situation at all. In risk governance, scientific advice can play a critical role in not only the routine but also emergency situation. During the Fukushima nuclear accident, the Japanese government experienced difficulties in taking wholly consistent action. For instance, a restricted area was set up immediately, but its range was subsequently enlarged several times and evacuation or precautionary safety measures were modified over time without due provision of detailed information to the local residents. In the case of catastrophic event with systemic nature, it is really difficult but important to coordinate and synthesize scientific inputs from many different fields and institutions and to translate them into useful policy advice at very short notice.

After the Fukushima, a few deficits are slightly corrected, but critical deficits still remain. Rather it seems that some deficits are getting worse. Behind these deficits, there may be affirmative awareness and attitude of 
justifying and maintaining the status quo. Even after the Fukushima, these still remain. As a consequence, even if certain warning signs are found, any contradiction with an existing plan or purpose led to reluctance toward recognizing them as such. Furthermore, since safety and security culture have not been rooted genuinely in the organization, countermeasures or corrective actions are postponed. It seems that a moral hazard of the thought still pervades all hierarchy, such as following the precedent, willful blindness, only formality, and autonomously deciding that the status quo is, for the most part, not negative. Vested interests may wish to keep the status quo.

Six year later, original risk issues have transformed to the wicked or complicated ones.

\section{Wicked Problems Orginated From the Fukushima Nuclear Disaster}

\section{Case-1: Prolonged Evacuation and Return to Hometown}

On March 11, 2011 the declaration of nuclear emergency situation, based on the Act on Special Measures Concerning Nuclear Emergency Preparedness, has been issued, subsequently the Prime Minister ordered the evacuation and sheltering of inhabitants to the heads of municipalities in Fukushima prefecture. The heads of towns and villages made a heavy decision on the entire evacuation with administrative functions to outside hometown. The caution areas set just after an accident were lifted in May, 2013 and the zones for evacuation order were re-categorized: "being prepared for lifting of order", "limit to live", "difficult to return for long-term". After the accident, the central and local governments have been pushing forward a policy of the early return unified with decontamination works, under continuing declaration of nuclear emergency situation. On March 31, 2017, the government lifted evacuation orders for zones "being prepared for lifting of order" and "limit to live". Municipalities where evacuation orders have been already lifted, however, have their own problems: a slow return of residents with many elderly returnees. According to the joint surveys mainly by the Reconstruction Agency (2017), in Iitate, Namie, and Kawamata's Yamaki district, the share of residents who responded they want to go back to their hometown was $33.5 \%, 17.5 \%$, and $43.9 \%$, respectively. As of July 2017, about 56,000 of the enforced and voluntary evacuees in both other area of Fukushima prefecture and other prefectures do not still return to their hometown (Fukushima 2017).

Behind this situation, there are weakening, collapse and disappearance of the entirety of the means to fill up for the fundamentals of living environment and people's appetites, such as safety and security of life, opportunities of labors, consumptions and people-to-people exchanges, and succession of local culture, that deeply interrelates with local natural environment (SCJ, 2014). Furthermore, there is a diversity of the actual situation and problem in the affected areas.

In such a background, the heads of municipalities that has been enforced evacuation of the entire residents strongly demanded implementation of the early return policy in order to intend to be as the municipality while an interrelation between residents and administrative organization is changing with prolonged evacuation (Abe, 2015). In response to this, the government enacted the Special Law for Evacuees due to nuclear accident in August 2011, and defined "evacuees" and "identified address movers" and prescribed the measures that should be taken by local governments concerned and the central government. The current return policy, however, is likely to affect feasibility of alternative effective measures because of enforcement of rigid and inflexible policy that is forced to make a choice between the early return and relocation by one's own efforts. The current policy has strongly an interrelation with compensation problems. For instance, if the government decides to lift the evacuation order for the identified zone, compensation for mental damages of victims in an identified area 
by the TEPCO is terminated regardless of reality of victim's return. There remains considerable controversy about the current return policy such as yielding of displaced persons and heavy financial burdens of local governments (Yamashita, 2017) ${ }^{1}$. The early return as a premise of the policy is complicated political problems for reconstructing and revitalizing the Fukushima. Essentially who should be beneficiaries of the return policy, only returnees and entities in hometown? The current policy lacks societal legitimacy and has political ambiguity. In spite of this reality, decontamination works and infrastructure rebuilding in zones of "difficult to return for long-term" such Okuma, Futaba and Namie are conducting by national budget aiming to lift the order within five years, according to the Act on Special Measures for the Reconstruction and Revitalization of Fukushima amended on 12 May 2017. The early return policy is more likely to fail, and consequently distort the reconstruction and revitalization of Fukushima, and eventually bring heavy burdens to our future generations.

Resident's cognitive dissonance against nuclear safety and radiation safety was dissolved by behavioral changes in form of the enforced and voluntary evacuations. Taking into account an uncertain situation of plant site and the reality of hometown, however, it is easy to imagine that the evacuees will not decide to dissolve current cognitive dissonance again in form of the return. In reality, it is hard to restrain loss of the will of the return under the prolonged evacuation.

\section{Case-2: Tokyo Electric Power Company Holdings Issues}

This wicked problem is originated from saving corporation that is already too big to fail. Shortly after the Fukushima nuclear accident, the government decided to preserve the TEPCO by temporal financial support through NDF (Nuclear Damage Compensation and Decommissioning Facilitation Corporation), which is an authorized corporation based on special law. In this scheme, TEPCO has been coping with compensation payments to victims and treatment of increasing contaminated water as a pressing challenge in parallel with organizational reform including streamlining of management and assets clearance for capital gains, under comprehensive special business plan approved by the government (Ministry of Economy, Trade and Industry-METI). Since 2013, operating capital needed for full-scale decontamination works, drastic countermeasures of contaminated water, and interim storage of radioactive wastes such as the removed soils surged. In 2016, TEPCO restructured organization, where its nuclear and decommissioning operations remaining under a holding company, and non-nuclear businesses spinning off into three subsidiaries (Fuel \& Power, Power Grid, Energy Partner).

With this background, METI set up two expert committees: "Committee for Reforming TEPCO and Overcoming 1F Challenges (closed)" (2016) and "Committee for Accomplishment of Electricity System Reform" (2017), and underlined that both TEPCO reform and institutional market reform would show the future of electric power industry, and in particular TEPCO reform is a fundamental challenge for Fukushima reconstruction, nuclear business, and nuclear energy policy.

The Accomplishment Committee mainly discussed how to cope with stranded cost arising from full liberalization of the electricity retail market from 2020, concretely, about preparation for compensation due to accident of and funding scheme for decommissioning of existing nuclear power plants (METI, 2017). First issue is how to collect expense ( 3.8 trillion JPY) that utility companies had to save before the Fukushima

\footnotetext{
${ }^{1}$ KGU Institute of Disaster Area Revitalization, Regrowth and Governance, 2012, Shinsai Nanmin-Genpatsu Kimin $1923-2011$. Retrieved from http://www.fukkou.net/publications /books /files/20130330.pdf
} 
nuclear accident; namely, utility companies are unable to save cost for contingency under the rate-of-return regulation. Second issue is also how to collect expense needed for decommissioning in the deregulated competitive environment after 2020. On these issues, the Committee recommends that scheme of the wheeling charge of electric power under the rate regulation, is desirable in order to collect without fail expenses concerned, and that it is important to impose an obligation on TEPCO to save up expenses in the NDF for decommissioning crippled reactors. It means that the additional costs will be eventually covered by means of electricity bills, that is to say, burden on the public.

In December 2016, The METI indicated at the TEPCO Reform Committee that total expected expenses for dealing with the accident will likely balloon from the initial expectations into a double, about 22 trillion JPY. With this information, the Committee discussed METI-led reform plan that consists of corporate business, nuclear business, Fukushima issues, and linkage of corporate business and Fukushima issues (METI, 2016). For instance, realignment of the major utilities' nuclear power divisions was proposed as an option of nuclear business strategy, as well as joint venture aiming at oversea market such JERA (TEPCO F\&P and Chubu EPC). In May 2017, the METI approved TEPCO Holdings' Third Comprehensive Special Business Plan reflecting the Committee's recommendations (NDF and TEPCO Holdings, 2017). TEPCO should keep annual profits 500 billion JPY including 100 billion JPY through restarting the Kashiwazaki-Kariwa nuclear power plants, for next 30 years.

The Japan Center for Economic Research (JCER) (2017), a private think tank, announced that total cost of the Fukushima nuclear disaster could reach 70 trillion JPY ( $\$ 626$ billion), or more than three times of the government's latest estimate. The JCER argues that treating the contaminated water stored in hundreds of tanks at the plant will cost 20 trillion JPY unless it is dumped into the ocean after being diluted as recommended by the Nuclear Regulation Authority (NRA). In reality, Fukushima Daiichi onsite management strategy is undoubtedly expected not going on as planned due to not only the underlying logistical problems such as financing and workforces but also technological difficulty of melted debris removal.

Fulfilling its responsibilities for the Fukushima nuclear disaster as well as establishing sustainable revenue base for corporate revival in competitive environment are severe challenges, and its feasibility may be extremely uncertain. If they (TEPCO and/or METI) run after two hares, they will catch neither. Saving corporations that are already too big to fail is extremely difficult. It needs responsible and forward thinking, and cool-headed judgment. If not, history proves that after a bailout they are usually so enfeebled and dysfunctional that they have trouble succeeding, and once bailed out they frequently fail again.

\section{Case-3: Nuclear Regulatory Issues}

Following the Fukushima nuclear disaster on March 11, 2011, the cabinet adopted a basic policy on the reform of an organization in charge of nuclear safety regulation on August 15, 2011. After the consultation with the opposition party at the time, Liberal Democratic Party (LDP), the act to establish the NRA, independent administrative committee under the Ministry of Environment, was passed on June 20, 2012. In September 2012, the government appointed five NRA members and had it started its activities (the Diet approval of the NRA members only came in February 2013). This NRA has more independent status compared to the previous safety regime and human personnel composing the authority is more than one thousand, because it incorporates former independent administrative agency, Nuclear Industrial and Safety Agency, into the ministry. Then can the NRA cope with issues exemplified by the Fukushima nuclear disaster and possible following events? 
Fukushima nuclear disaster can be characterized as the extreme case of Natech event that is defined as the technological disaster event caused by natural disaster (Cruz et al., 2004). In this respect, Fukushima nuclear disaster has made it clear that there was a severe delay in implementing tsunami countermeasures (Shiroyama, 2016). In Japan, there had been a delay in taking actions to deal with seismic and tsunami risks although there are some progress in earthquake countermeasures. In September 2006, the Nuclear Safety Commission of Japan (NSC) revised the regulatory guide for reviewing seismic design of nuclear power reactor facilities based on the results of the five-year study by the Subcommittee for the Regulatory Guide for Reviewing Seismic Design. These processes, however, had not gone smoothly. In particular, there was a communication gap between the expert community on nuclear reactor safety, which consisted mainly of those in the engineering field, and that of earthquake, which was made up of those in the scientific field. The same kind of interdisciplinary communication issues continue even for seismic risks. As to the tsunami countermeasures, the Japanese nuclear community was unable to incorporate the rapid scientific progress in understanding tsunamis. For instance, in August 2002, the Earthquake Research Committee of the Headquarters for Earthquake Research Promotion, led mainly by scientists, pointed out the possibility of earthquakes centered in plate boundary ocean areas which can be stronger than historical ones. The result was conveyed to the Central Disaster Management Council at the cabinet, but the council did not pay serious attention to the possibility on the ground that it needs to prioritize disaster countermeasures from the viewpoint of overall disaster management policy. In addition, new simulation methods combined with sedimentological studies brought some new findings on the Joggan earthquake of 869 mentioned in reliable historical records. Based on these findings, some tsunami experts estimated possible tsunami levels in the Fukushima coastal area higher than earlier predictions. Such advances in tsunami research have made the uncertainty of tsunami prediction more evident among the tsunami experts' community. Nevertheless, their recognition of this uncertainty was not transmitted to the nuclear safety community. In the revised regulatory guide aforementioned, tsunamis were treated only as part of the "accompanying phenomena" of earthquakes. It can be seen from the above that insufficient interdisciplinary communication, facilitated by narrow thinking and framing of each discipline, was one of the background factors in the delay in taking actions against tsunami risks.

The NRA discussed, decided, and implemented stricter new safety standards in July 2013. Those standards legally include severe accident management procedure (4th level component of defense in depth) to deal with severe accidents beyond design basis such as tsunami and earthquake. Relating earthquake, now the NRA examines the active faults up to 400,000 years and heated debates among experts can be found. The cross-sectoral issues which need to be managed, however, are not limited to issues between nuclear safety and earthquake/tsunami. It can be observed between nuclear safety and volcano, and nuclear safety and solar storm. The NRA just started to discuss about the volcano issues but under much shorter time frame compared to the active faults recently, and did not talk about the solar storm issues yet. It can be said that the NRA began to consider cross-sectoral issues but only under the limited scope.

Another regulatory issue which was not dealt with fully is emergency evacuation program. Though emergency evacuation program is essential as the 5th component of the defense in depth, it is made by local governments and is not included legally in the nuclear safety regulatory regime. So the NRA made the guideline on emergency evacuation plan but does not have formal authority to review and approve emergency evacuation plan. Only Nuclear Disaster Management Council of Related Ministers reviews those plans. Important coordination between prefectural government, municipalities, and central government is left for 
informal coordination, beyond the scope of nuclear safety regulation.

\section{Case-4: Nuclear Energy Policy and Nuclear Business}

As mentioned before, nuclear power in Japan was a major part of electric power supply system that forms the fundamentals of critical infrastructures in the society before the Fukushima accident; the use of nuclear power has been tightly and complexly interconnected with and interdependent on socio-economic activities so far and also produced the nested or collective interests everywhere as results of nuclear technological and institutional lock-in phenomena (Taniguchi, 2016b).

Fukushima nuclear accident reignited public and political debates, and led to not only re-examination and improvements of institutional framework and their activities of nuclear safety regulation but also revisiting about national policy of nuclear energy use. Social trusts in the government and nuclear fraternity have been seriously eroded. In the light of a strong public sentiment of aversion against nuclear power in the aftermath of the Fukushima nuclear crisis, of course, not only the general public also nuclear fraternity had high expectation of sweeping change. Both the government and the diet, however, have approved the reform of nuclear safety regulatory bodies in June 2012 without reflecting the findings and recommendations of the National Diet Commission's final report.

As for the nuclear energy policy in Japan, the government by the ruling Democratic Party of Japan established the Energy and Environment Council in the Cabinet Office in October 2011 and decided the Innovative Energy and Environment Strategy including nuclear phase-out scenario through expert meetings, public hearings, and the deliberative poll in September 2012. A few months later, however, Japanese energy policy once more has been drifting caused by a dramatic LDP's win at the general election in December 2012. Since institutional reforms in 2014, the Cabinet and METI-ANRE lead nuclear policy-making and decisions without organizing opportunities of inclusive dialogues, where public sentiment is even changing to being ambivalent to nuclear energy. Moreover, assignment of the role and responsibility between the central and local government do not change at all, that is to say, the government's roles in nuclear power policy and its implementation are limited, rather local government plays a key role and shoulders a heavy decision substantially.

As for restart of power plants, on the one hand, as of June 2017, 12 Pressurized water reactor (PWR) plants passed the NRA's examination of conformity with new nuclear safety standards, and five of those are in commercial operation again ${ }^{2}$. On the other hand, Boiling water reactor (BWR) owners cannot foresee reactors back online. As noted above, local government shoulders a heavy decision substantially. For instance, prefectural government and municipalities within $30 \mathrm{~km}$ radius from the plant are tasked with drawing up and carrying out emergency evacuation programs, the roles of the central government have not been spelled out. Additionally, the NRA is responsible for only technical aspects of plant safety except emergency response and recovery. Looking at the scenes in the process of nuclear power restarting, it can be still observed subsidy-based relation and negotiation and DAD (Decide, Announce, and Defend)-based one-way communication activities by the government. Local communities and the pro-nuclear local chapters of the LDP, in reality, rely heavily on central government subsidies and utility donations that come with hosting power plant. Such relationship between the central and local government is likely to be more paternalistic one before ever. This past approach has already reached a limit. Recovering trust by deterrence such surveillance and

\footnotetext{
${ }^{2}$ Federation of Electric Power Companies of Japan (FEPC), 2017. Retrieved from http://www.fepc.or.jp/theme/re-operation/
} 
sanctions fall likely into an infinite loop that creates a costly society. Additionally, the result is merely security through application of external force and does not build a genuine trustworthy relationship.

The Abe administration, under the basic energy plan revised in 2014 has already decided it will activate reactors that have cleared nuclear safety standards by the NRA. Political intervention in nuclear power issues without serious efforts for deliberating its use in the future with the public and correcting deficits of risk governance, and decision-making among only politicians and local government in the name of energy security, local economic revitalization and climate change tackling, are concerned. Additionally, human resource problem is getting worse and worse. During shutdown of power plant for six years and more, inexperienced young operators are increasing in each plant site. Serious vulnerabilities may exist as a result of a retiring work force or lack of skilled labor in Japan. Skilled operators are necessary for infrastructure maintenance and, therefore, security and resilience. Such fundamentals underpinning nuclear power operation and maintenance works are collapsing sharply and irreversibly. Development of skilled-labors and professionals in plant site, nuclear industry as well as regulatory body, is critical challenge.

Meanwhile, utility companies decided the dismantling of six aged reactors since 2015 and have no motivation of constructing or replacing new power plants because of severe nuclear business expected in a pressing competitive environment. Furthermore the government's bid for nuclear fuel cycle such as Monju prototype fluidized bed reactor (FBR) remained elusive due to the failure or delays of costly projects and decided its decommissioning in December 2016.

Such energy plan seems incongruous, and is likely to come to nothing, taking into account current socio-political circumstance. Among others, Japan's energy transition policy aiming at low carbon society tends to deviate politically and now at crossroad. Nuclear power will be continuing tightrope walking over a couple of decades. It is important to break a vicious circle.

\section{Underlying Common Causes in Wicked Problems}

\section{Mutual Distrust Structure and Perception Gaps}

In the case-1, evacuation order, decontamination criteria, and their scientific and political grounds yielded directly and indirectly not only physical impacts due to radiological exposures to residents, agricultural, and livestock products but also non-physical impacts such as mental stress, discomfort, and adverse reputations. In particular non-physical impacts were amplified by uncertainties and ambiguities of scientific evidences, delay of delivery and little by little disclosure of information, media coverage focusing on sensational adverse events, uneasiness about invisible threats, lacks of expertise and integrity of risk managers and decision-makers and forbearance of moral and political responsibilities, and consequently mutual distrust yielded among people and entities concerned.

In such situation, various signals (images, signs, symbols) and information intensifying or attenuating in societal process yielded thought contagion and sometimes brought about economic contagion. For example, trading prices of rice produced in Fukushima prefecture has been fixed to be cheaper than the national average, even though not only there has not been anything beyond the regulatory criteria in inspection of radioactive substances since 2015 but also most of people outside Fukushima currently say that they choose from Fukushima prefecture, or do not care about production areas (NHK, 2017). Moreover, distributors (wholesalers and retailers of Fukushima's rice) are thinking that consumers refused more than the actual situation above noted. A cause of this example is perception gap arising from one-sided belief of distributors. It will probably 
affect mutual trust between producers and distributors in supply chain of Fukushima's rice.

In the case- 2 as well as above noted, there is mutual distrust among stakeholders such as victims, the local governments, central government, the media, other utility companies, and the public. We sometimes hear these complaints: The scientists or technical experts sometimes complain, "Our work is complex and technical. Lay people cannot understand it..."; the public also complain, "The politicians don't listen. They just want to get re-elected..."; the policy-makers say, "All we get from the public are endless complaints. We are doing best we can...". Under such circumstance, if the financial, social, and political stakes arise, problems concerned become more adversarial and disputatious, eventually wicked or complicated ones. Complaints easily alter to distrust and lead us to trap into a vicious circle.

In the case-3 as well, we can see distrust among experts in different disciplines. Especially experts in earthquake and tsunami area tend to have feeling that their expertise was not well treated during the process for discussion of regulatory arrangement before Fukushima nuclear disaster, and they tend to be aggressive during the process of negotiation of new regulatory standards.

\section{Following the Precedent and Institutional Lock-in}

In the case of the return policy, harmful influences caused by not only rigid and inflexible policy attaching importance to follow the precedent but also departmentalization and pillarization of administrative organizations can be observed. Additionally, decision-makers, Rather than examining all possible alternatives, simply search until they find a solution that meets a certain acceptable level of performance (Bazerman, 2002). Following the precedents that are feasible or easy to implement hinders challenging initiatives and alternative policies, and eventually are likely to transform or fragment the purpose and original intention of the return policy (SCJ, 2014).

The government allotted huge budget to decontamination work that was the first of its kind in the zones affected by nuclear disaster, and took the lead in the work to achieve the early return policy. Consequently this course of action gave rise to rigid and inflexible framework. Even though the government (Ministry of Environment-MOE) recognizes limitation of performance of decontamination works, the MOE continued the works in terms of equality and uniformity and did not transfer its budget to alternative measures. Following the precedent can be observed also in the process of lifting evacuation order.

There is institutional lock-in that path-dependency of the current return policy potentially gives rise, such as vested or collective interests, escalating commitment, cost overrun, and inflexibility and the closure of alternatives. Lock-in can occur both at decision-making level before the decision to build and at the project level after the decision to build. Vested interests may wish to keep the status quo. Needless to say, a root cause of deadlocked nuclear energy policy is institutional lock-in due to subsidy-based policies that strengthened technological lock-in phenomena.

Moreover, "to-much-invest-to-quit" effect in decision-making leads to affirmative awareness and attitude of justifying and maintaining the status quo: that is to say, to ensure consistency and integrity with past explanation on safety assurance and policy to local governments and residents, to reduce or avoid too much impacts to the operating power plants and lawsuit against permission of nuclear facility installation (keeping infallibility of regulations). Consequently, even if certain signs were found, any contradiction with an existing plan or purpose led to reluctance toward recognizing them as such (Taniguchi, 2016b). 


\section{Myopic and Narrow Thinking}

What behavior will be manifested in socio-economic-political system as a whole as the outcome of changes of endogenous conditions through the interaction among the individual agents and entities? The present wicked problems resulted from inaction of continuous consideration and understanding about this question. It is a critical deficit of risk governance in interconnected society. So far the Fukushima problems have been addressed by the restricted stakeholders in the limited contexts such us nuclear safety regulation and nuclear energy policy without including the relevant policy domains. TEPCO and the government have taken actions with myopic and narrow views in worrying too much about loss of trustworthiness in local society concerned rather than whole society, while evading realistic estimates and deliberations about future scenarios including wild card scenario. Even just for regulatory design, experts of different discipline have different perspectives and it is not easy to have cross-boundary discussion. As a result, policy options for dealing with our challenges become limited, consequently resilience of policy lost. Focusing on short-term consequences or impacts could enhance certainly the political feasibility of decision in terms of tactics, but fail to secure sustainability. Furthermore, "not-in-my-term-of-office" mentality are rampant everywhere, in particular in bureaucratic politics. This could also affect synergistically.

Politicians and executives officers of institutions often tend to give undue attentions and response to zero risk or absolute safety obsession without considering holistically risk tradeoff issues, only under a slogan of "securing safety and security (peace in mind)". Their behaviors would make distorted and inefficient policies. It reminds me of that nuclear fraternity's behaviors created nuclear safety myth. A delay of lifting of evacuation order is a typical example.

\section{Defects in the Institutions and Laws}

How to cope with stranded cost arising from full liberalization of the electricity retail market from 2020, as shown in the case-2, should anticipatorily have examined and institutionalized in the process of substantial debates of electricity market system reform since the middle of 2000s. There are still legislative and institutional defects in nuclear domain. For instance, three laws relating to nuclear disaster-Nuclear Reactor Regulation Law, Act on Compensation for Nuclear Damage, and Act on Special Measures Concerning Nuclear Emergency Preparedness-lack linkage and consistency in these contents because of under jurisdiction of different ministries. Stopgap measures against legislative and institutional defects would distort validity of policy and become a hotbed of future risks.

\section{Perspectives and Challenges for Managing the Wicked Problems}

Each of the wicked or complicated problems referred in this paper complexly interrelates. Emergency preparedness issues are affected by the Fukushima's tragedy and consequently influences policy-making of future nuclear energy use. TEPCO reform issues definitely influence both the reconstruction of affected communities in Fukushima prefecture and nuclear business, eventually also nuclear energy policy. Nuclear energy utilization and public confidence in nuclear fraternity would deeply be influenced by future course of cross-governmental policies for reconstructing the affected communities.

Common viewpoints needed for addressing such problems are long-term, cross-sectoral, and holistic perspectives beyond question. Most of cascading events originated in the Fukushima nuclear disaster are not the "unexpected" or "unforeseeable" consequences. In particular, four problems addressed in this paper can be 
anticipated and prevented to become wicked or complicated issues, if keeping the movement of policies concerned under observation. As lessons learned from the Fukushima nuclear disaster, some perspectives and challenges required to govern interconnected events are as follows:

(1) A disruption of one element, such as infrastructure, causes a sequence of disruptive events, so-called cascading, which can cause deleterious impacts far beyond the initial impacts of the initiating event. As noted before, Fukushima nuclear accident brought about a lot of events with multi-faceted nature through cascading or ripple effects in the interconnected fabric of the society. In general, because of the interconnectivity, it is often difficult to predict how a crisis will unfold, what it will affect, and how effects further shape the unfolding of the crisis. The unpredictability and uncertainty commonly contribute to the magnitude of the catastrophic consequences. Is cascading or ripple effects really unavoidable? No, at least there are avoidable events, and it is able to mitigate magnitude of adverse impact of subsequent event. For that, decision-maker should take full responsibility and provide prospect for settlement of event concerned.

(2) Interconnectivities and interdependencies in our socio-economic-political system are brought into relief particularly in emergency response and recovery processes as demonstrated in the Fukushima. It means to be important to holistically appreciate in terms of system of systems rather than a single system. We have to acknowledge the higher levels of connectivity that already exist, drivers and surprising system behaviors of systemic instabilities (Helbing, 2013). Policy makers should be constantly vigilant about interconnectivity and their potential consequences and apply such information to design governance scheme for dealing with complex issues.

(3) With above-noted knowledge, we have to break through embedded cognitive barriers to imagine events outside the boundaries of accepted paradigms. What is necessary as well is a focus on creativity and openness to imagining the atypical, singular, exceptional or even inconceivable. This requires integrating lateral thinkers, including people from outside the established circles, in order to contemplate the unknown.

(4) Adjusting to the new environment will require thought and action different from what we have done in the past. Incremental changes and modifications based on the insights and understandings gleaned from the process of implementation, won't work in today's over-connected environments. Tinkering with existing dysfunctional systems will probably never create ones that function well. Policy makers should acknowledge that small fixes of big problems frequently contribute to still bigger ones, that is to say, the perils of putting Band-Aids on problems (Davidow, 2011).

(5) While the risks might seem manageable when examined individually, they could be troublesome when they hit in tandem. At the heart of managing interconnected events is understanding of who bears the risks and who reaps potential benefits, so that incentives can be aligned in an appropriate manner.

(6) In general, regulations are narrowly focused, tailored specific activities or industries, and aimed to prevent malicious acts, accidents, or disasters. In complex society, however, critical secondary or spillover effects also occur beyond any given initial activity. Therefore we should monitor these consequences. Furthermore, we must acknowledge that regulations themselves can trigger unintended or unforeseen consequences. The impossibility of predicting effects of regulations in complex systems also implies a need for an iterative and incremental learning process. For that reason, it needs to set up institutional scheme for enabling regulatory authorities to communicate closely, collaborate and share knowledge beyond the own jurisdiction in order to ensure a coordinated response to major incidents with cross-sectoral impacts. 
(7) In order to restore mutual trust or rebuild public relations, the extended perspective approving of shared thinking and collaborative efforts that raise the quality of social relationships is needed. Restoration of trust emerges from self-initiated action, and not from external leverage. Trust, or lack of trust, is perceived to be a crucial factor in how risks may manifest themselves. "The major risks are social", but they are still poorly understood (Helbing, 2010). Risk is a highly interdisciplinary phenomenon and it takes an integrated view from all of different perspectives to get it right (Morgan, 2015). Cultivating mutual trustworthiness and filling perception gaps among stakeholders are essential for effective governance of cross-sectoral events. For that reason, we should change the prevalent culture of avoiding open discussion of risks in Japan.

\section{References}

Abe, M. (2015). Zenchouhinan • Zensonhinan to Chihojichi. In T. Ohara, \& H. Inatsugu (Eds.), Shinsaigo no Jichitai Gabanansu (pp. 49-71). Toyo Keizai Shinpousha.

Bazerman, M. H. (2002). Judgment in managerial decision making (5th ed.). Publisher: John Wiley \& Sons.

Cruz, A. M., Steinberg, L. J., Lisa, A., Arellano, V., Nordvik, JP., \& Pisano, F. (2004). State of the art in Natech risk management. European Commission Joint Research Center.

Davidow, W. (2011). Overconnected: What the digital economy says about us. London: Headline Book Publishing.

Helbing D. (2010). Systemic risks in society and economics. Retrieved from http://irgc.org/Project-Overview.219.html

Helbing D. (2013). Globally networked risks and how to respond. Nature, 497, 51-59.

Japan Center for Economic Research. (2017). Accident cleanup costs may rise to 50-70 trillion yen. Retrieved from http://www.jcer.or.jp/eng/research/policy.html

Ministry of Economy, Trade and Industry. (2016). Committee for Reforming TEPCO and Overcoming 1F Challenges: $\begin{array}{lllll}\text { Recommendations } & \text { on } & \text { TEPCO } & \text { Retrieved }\end{array}$ http://www.meti.go.jp/committee/kenkyukai/energy_environment/touden_1f/pdf/161220_teigen.pdf

Ministry of Economy, Trade and Industry. (2017). Committee for Accomplishment of Electricity System Reform: Interim Report. Retrieved from http://www.meti.go.jp/report/whitepaper/data/pdf/20170209002_01.pdf

Morgan, G. (2015). IRGC 2003-2013: Interviews with IRGC academics. International Risk Governance Council. Retrieved from http://www.irgc.org/wp-content/uploads/2014/05/IRGC-10-YEARS-WEB.pdf

NDF and TEPCO Holdings. (2017). Third Comprehensive Special Business Plan. Retrieved from http://www.meti.go.jp/press/2017/05/20170518004/20170518004-1.pdf

NHK. (2017). Closeup Gendai+: Anzen nanoni Urenai Fukushima Aratana Fuhyouhigai. Retrieved from http://www.nhk.or.jp/gendai/articles/3979/index.html

Reconstruction Agency. (2017). FY2016 Survey on public awareness in municipalities affected by nuclear disaster: Survey results. Retrieved from http://www.reconstruction.go.jp/topics/main-cat1/sub-cat14/ikoucyousa/20170307_ikouchousa_zentai_gaiyou.pdf

Science Council of Japan (SCJ). (2014). Recommendations on improvements of policy for reconstruction from East Japan mega disaster. Retrieved from http://www.scj.go.jp/ja/info/kohyo/pdf/kohyo-22-t200-1.pdf

Shiroyama, H. (2016). Nuclear safety regulation before the Fukushima accident and post-accident reform. In K. Tsunekawa (Ed.), Five years after: Reassessing Japan's responses to the earthquake, tsunami, and the nuclear disaster (pp. 57-79). University of Tokyo Press.

Taniguchi, T. (2016a). Technology assessment and risk governance: Challenges ahead in Japan. In A. Moniz, \& K. Okuwada (Eds.), Technology assessment in Japan and Europe (pp. 23-35). KIT Scientific Publishing.

Taniguchi, T. (2016b). Risk governance deficits in Japanese nuclear fraternity. Journal of Science and Technology Studies, 12, 242-259.

World Economic Forum (WEF). (2010). Global Risks 2010: A global risk network report. Retrieved from http://www.oliverwyman.de/content/dam/oliver-wyman/global/en/files/archive/2011/Global_Risk_2010.pdf

World Economic Forum (WEF). (2012). Global Risks 2012 Seventh Edition. Retrieved from http://www.ledevoir.com/documents/pdf/davos2012.pdf

Yamashita, Y. (2017). Fukkou ga ubau chiiki no mirai. Publisher: Iwanami Shoten. 